\title{
Coproducing spatial information: Exploring govern- ment approaches and motivations at the local level
}

\author{
Zarin T. Khan, ${ }^{1^{*}}$ Peter A. Johnson ${ }^{2}$ \\ $1^{1 *}$ ORCID Nr: 0000-0002-3652-9972 \\ Department of Geography \& Environmental Management, University of Waterloo, 200 University Ave W, \\ Waterloo, ON N2L 3G1, zt2khan@uwaterloo.ca \\ 2 ORCID Nr: 0000-0003-4572-2915 \\ Department of Geography \& Environmental Management, University of Waterloo, 200 University Ave W, \\ Waterloo, ON N2L 3G1, peter.johnson@uwaterloo.ca
}

\begin{abstract}
Recent government initiatives like e-government and open government have led to broader adoption of geospatial tools including mapping platforms to access, use, and analyze open data. These advancements open channels for coproduction in the form of sharing information, change notifications, opinions, or requests to government, based on citizen observation and local knowledge. Though current government initiatives have substantial potential for coproduction, the practical adoption and implementation of such practices vary reflecting the purposes, contexts, and motivations of those involved. This paper aims to understand how local governments are following different approaches to coproduce information with citizens and what motivates local governments in this process. We report findings based on interviews with 11 cities from the USA and Canada, which reveal four main approaches: the collection of new data, observation of changes, collection of opinions, and observation of preferences involving both explicit and implicit processes. Although these four approaches result from interactions between citizens and government, our findings also indicate a key role to be played by technology and partner organizations.
\end{abstract}

Keywords: Coproduction, digital government, spatial information, GIS, open government

Acknowledgement: This research was funded by Social Sciences and Humanities Research Council of Canada. We would also like to thank all the interviewees who participated in our study for taking time to share their insights. 


\section{Introduction}

The recent emergence of digital governance in the form of e-government, open innovation, and smart city initiatives, demonstrates coproduction approaches to produce spatial information. Although governments have a long history of coproduction of services with citizens, digital platforms to collect and share information have made it easier to adopt various coproduction approaches (Falco \& Kleinhans, 2019; Linders, 2012). Digital government plays a major role in this transformation, enabling citizens, regardless of their expertise and background, to coproduce information with government, conveying their observations and sharing opinions and feedback about their views and activities (O'Reilly, 2009). These approaches further provide opportunities to create an inclusive and participatory government by sharing data and collecting feedback to support planning and decision-making (Bennet \& Harvey, 2009; Graves \& Hendler, 2014; Robinson \& Johnson, 2016).

The majority of data required for planning and management at the local level have geographic characteristics, requiring the use of geospatial tools such as mapping platforms, to coproduce information with citizens (Falco \& Kleinhans, 2019; Johnson, 2017). This availability of tools encourages governments to gather local knowledge through citizen contributions. With the strategic and technical expertise of government and local knowledge sourced from various coproduction approaches, governments aim to comprehensively plan for service delivery (Konsti-Laakso, 2017). Thus, these practices can have a promising impact in improving governance. Although coproducing information can allow social and economic innovation (Voorberg, Bekkers, \& Tummers, 2015), development and management of the system is a complex task and is often challenging, as government has its own capacity and resources limitations. The challenge of managing the limitations of government capacity and providing a systematic process of information collection, leads to the development of partnerships with experts from research or private organizations (Attard et al., 2016; Cardullo \& Kitchin, 2018; Johnson et al., 2015). This indicates that, although coproduction of information is a process between citizens and government, there are other entities involved, that may have a significant role in facilitating and shaping the coproduction process.

There is a current research gap in understanding how coproduction approaches in digital government can influence social issues such as democratic power, sharing control with non-government agencies, or emotional aspects like autonomy of citizens (Bates, 2014; Chatfield and Reddick, 2018; Janssen \& Zuiderwijk, 2014; Johnson and Robinson, 2014; Loeffler and Bovaird, 2016; Thomsen, Baekgaard \& Jensen, 2020). It is also crucial to understand how communications between government and citizens is evolving through coproduction on digital platforms and how information is being produced and used (Konsti-Laakso, 2017). In this paper we address this gap by answering how and why, local governments are practicing coproduction of spatial information. Answering this question is necessary as it can reflect on the impact of coproduction on democratic, social, cultural, and commercial transformation of our society. We investigate our research question by focusing on several case studies at the local level in North America to explore what approaches are being used by government, and what factors may be motivating them to adopt coproduction approaches. 


\section{Literature review}

There is a wide range of academic discussion on coproduction between government and citizens. Coproduction in government is generally seen as a process of producing information with citizen contributions for better service delivery (Konsti-Laakso, 2017; Linders, 2012; Liu, 2021; Loeffler \& Bovaird, 2016). Information contribution can range from designing a service to providing feedback to government about the service. Studies show that there is a strong role for ICT within the process, and often communication between citizens and governments is built on open data, such as government planning proposals or existing, but outdated, geospatial data (Hong, 2016; Linders, 2012). While coproduction involves citizens contributing information, there are several terminologies such as Volunteered Geographic Information or VGI, Public Participatory Geographic Information System or PPGIS, or crowdsourcing which can be used to describe similar processes (Falco \& Kleinhans, 2019; Khan \& Johnson, 2020; Liu, 2021; Sangiambut \& Sieber, 2016). Moreover, contributions by individuals can often be labelled as citizen participation, engagement, or involvement (Bovaird, 2007; Linders 2012). In this section, we briefly review literature to develop a conceptual synthesis of the terminologies for a clearer understanding of the characteristics of coproduction.

\subsection{Coproduction}

As Liu mentioned, within discussing a typology for crowdsourcing in government, "Crowdsourcing thus serves as a vehicle for citizens to coproduce public services" (Liu, 2021; pp.14). This portrays the connection between crowdsourcing and coproduction. Coproducing public service with government often involves crowdsourcing geographic information from citizens, this particular act where citizens contribute with geographic information or insights is very similar, widely common, and considered as VGI (Sangiambut \& Sieber, 2016). VGI refers to citizen contribution of geospatial data and knowledge often used in governments to gather local knowledge and provide better services (Brabham, 2015; Clark \& Brudney, 2019; Goodchild, 2007). In addition, coproduction of information in the planning sector also takes place through PPGIS, where government demonstrates a planning proposal using digital mapping platforms and citizens then share their comments and opinions on the proposal (Hall et al., 2010; Kahila-Tani et al., 2016; Sieber, 2006). Not all these approaches involve the active contribution of citizens. The collection of geospatial data is also conducted by harvesting information created for other purposes. For instance, reviews of places or services shared on the internet (Rahimi et al., 2018), opinions or thoughts shared on social media (Zhang \& Feick, 2016), or GPS tracks produced during travelling (Attard et al., 2016). Due to the implicit nature of contribution, these processes of harvesting geographic information created by citizens for other purposes are categorized as passive VGI (Craglia et al., 2012; Senaratne et al., 2017), also considered as involuntary VGI or iVGI (Fischer, 2012). Summarizing these terminologies, for the purposes of this paper, coproduction of spatial information is considered as a process that involves crowdsourcing such as VGI, and can use different tools such as PPGIS, or harvesting citizen contributed information from various internet sources. Nevertheless, coproduction also has a strong relevance with the term cocreation and both are used in public service and administration contexts. However, the level of engagement can vary in these two processes. According to Brandsen and Honingh (2018) in cocreation, citizen involvement occurs at an early strategic development phase of decision-making or planning, usually for the design and development tasks. Coproduction, on the other hand, has a stronger focus 
on collecting necessary information with government, which is common in implementation and service delivery processes (Brandsen \& Honingh, 2018). The fact that cocreation involves citizens more at the creation and design level and coproduction centres around the implementation of services makes coproduction a more appropriate term for the processes discussed in this paper.

\subsection{Role of coproducers}

Citizen contribution in coproduction is often labelled as citizen engagement and citizen participation. These terms commonly refer to the active involvement of citizens in government actions or decision-making although there is no specific or broadly accepted definition and distinction between these two. According to Nelson and Stenberg, citizen participation is an evolved terminology from citizen involvement, which with time has further evolved and used as engagement (Nelson \& Stenberg, 2017, p. 154). This matches with Arnstein's conception of citizen participation where they emphasized the distribution of power and control in participation that allows citizens to be 'included and benefitted from the affluent society' (Arnstein, 1969, p. 216). Similarly, the notion of engagement reflects a similar sense of power with active and conscious involvement of citizens requiring deliberate attention and energy to participate (Berger, 2009).

Among these variations of the terms and concepts about participation and engagement, Linders (2012) used the term coproduction considering the advancements of communication provided by digital government and suggested that the role of citizens is changing from engagement or participation to coproduction of information and services with the government. Similar nuance of the changing relation between citizens and government is reflected in Bovaird's (2007) work, he found that coproduction practices are found useful and beneficial as a part of government system as the traditional service delivery methods are often considered outdated. Among these government practices, coproduction may not always mean active involvement or empowerment, rather emphasize economic benefits such as improving service delivery (Voorberg, Bekkers, \& Tummers, 2014; Tenney and Sieber, 2016). Considering these concepts and the current practices of government, we use the term coproduction representing the practices of collecting spatial information through a collaboration between citizens and the government.

\subsection{Coproduction in government}

With recent advancements in digital governance, coproduction approaches are increasingly being undertaken by local governments. Linders (2012) suggests that coproduction results in three directions of communication including government to citizens, citizens to government, and citizens to citizens. The author addresses three primary components required for coproduction: citizens, government, and ICT based platforms. Zhang (2018) identified three categories of geo-participation at the local level including consultative, such as PPGIS, transactional, which involve civic issue trackers, and passive geo-participation, involving social sensing or harvesting of GI. While these forms of geo-participation are practiced for acquiring new GI created through citizen input, the technology platforms are also being used to edit or update existing authoritative databases which are actively contributed by non-experts or citizens to support government with current information. For instance, Johnson (2017) identified four models of citizens directly editing authoritative geospatial 
data including status quo, data mirroring, data curation, and crowdsourcing. The adoption of these models vary, based on organizational and technical contexts, to support data collection and editing processes of government. These identified processes are found to empower citizens (Goodchild, 2007; Sieber, 2006), and more importantly create a partner-like relationship (Linders, 2012) with a collaborative goal for better planning, decision-making, and service delivery. Thus, depending on organizational arrangements, availability of resources, and desired benefits, government may take different coproduction approaches.

\section{Methods}

The results of this study are based on case studies at local government level. Initially, the cities were selected based on available documentation on their website or in online reports. Affiliated officials in the division or project, involving coproduction approaches were invited for interview. Based on the responses, a list of cities was developed that showcases coproduction projects that focus on spatial information. Furthermore, at the end of the interviews, we asked respondents about other cities/projects they are aware of that follow a coproduction approach. Following this snowball approach, we finally reached out to more affiliated officials in other cities for interviews. In order to ensure completion of the research work, we followed a specific timeline, and the process of invitation and interviews took place from September to November of 2018. The final list of all cities with the responsible divisions is mentioned in Table 1 . A total of 12 participants were interviewed. The participants are from the mentioned division in Table 1, who are closely handling the project.

The list included cities that;

a) are using mapping platforms or tools to visualize open data and collect updates and feedback,

b) have specific citizen engagement platforms to collect citizen opinions and views (such as PPGIS),

c) have experience with, or plans for collecting specific information through citizen contribution, and

d) are using existing tools and platforms from third parties to collect and use information from citizens.

Along with these city-based projects, the Connected Citizen Program was also included, as an example of how a third party (Waze) is working in close collaboration with local governments to coproduce traffic information with citizens. 
Table 1: List of cases

\begin{tabular}{|c|c|c|c|c|}
\hline & Organization & Population & Division & $\begin{array}{l}\text { Co-production ap- } \\
\text { proach }\end{array}$ \\
\hline 1 & City of Barrie & 141,4301 & GIS & Observation of changes \\
\hline 2 & City of Brampton & $\begin{array}{l}\text { 593,635Error! } \\
\text { Bookmark not } \\
\text { defined. }\end{array}$ & GIS & Observation of changes \\
\hline 3 & City of Calgary & $\begin{array}{l}\text { 1,239,609Error! } \\
\text { Bookmark not } \\
\text { defined. }\end{array}$ & Planning & Collecting opinions \\
\hline 4 & City of Cambridge & $\begin{array}{l}\text { 1,08,757Error! } \\
\text { Bookmark not } \\
\text { defined. }\end{array}$ & GIS & Collection of new data \\
\hline 5 & City of Guelph & $\begin{array}{l}\text { 131,794Error! } \\
\text { Bookmark not } \\
\text { defined. }\end{array}$ & Planning & Collecting opinions \\
\hline 6 & City of John's creek & 83,6372 & Communication & Collection of new data \\
\hline 7 & City of Kitchener & $\begin{array}{l}\text { 233,220Error! } \\
\text { Bookmark not } \\
\text { defined. }\end{array}$ & GIS & Observation of changes \\
\hline 8 & City of Ottawa & $\begin{array}{l}\text { 934,240Error! } \\
\text { Bookmark not } \\
\text { defined. }\end{array}$ & Planning & Collection of new data \\
\hline 9 & $\begin{array}{l}\text { City of Washington, } \\
\text { DC }\end{array}$ & $684,498^{2}$ & Transportation & Collection of new data \\
\hline 10 & City of Waterloo & $\begin{array}{l}\text { 104,986Error! } \\
\text { Bookmark not } \\
\text { defined. }\end{array}$ & GIS & $\begin{array}{l}\text { Collection of new data } \\
\text { Observation of changes }\end{array}$ \\
\hline 11 & City of Winnipeg & $\begin{array}{l}\text { 705,245Error! } \\
\text { Bookmark not } \\
\text { defined. }\end{array}$ & Transportation & $\begin{array}{l}\text { Observation of changes } \\
\text { Observation of preferences }\end{array}$ \\
\hline
\end{tabular}

Population Census 2016. Source: Statistics Canada

Population Estimates 2018, Source: US Census Bureau 


\begin{tabular}{|c|r|c|c|}
\begin{tabular}{c|c} 
Waze-ESRI partnership \\
with local government
\end{tabular} & $\begin{array}{r}72 \text { city partners } \\
\text { in North America }\end{array}$ & GIS & $\begin{array}{r}\text { Observation of changes } \\
\text { Observation of preferences }\end{array}$ \\
\hline
\end{tabular}

Based availability of the officials and official documentation of the cases, 11 local government cases were considered for this study. Officials from these cases were interviewed with semi-structured questions. The interviews were conducted using telephone or web calls, recorded with respondents' permission. The information and observation from the discussion were noted and transcribed, then coded for analysis. We followed grounded theory for our analysis with open coding to identify the approaches and driving factors for coproduction. This means that the development of our concepts and analysis grounded on the data from our interview and during data analysis we asked questions such as 'what category does this statement fall into?' or 'does this part share similar or different nuance than other respondents on a specific topic?' to develop the codes for analysis (Thornberg \& Charmaz, 2014). Using coding, different aspects from the interviews such as 'type of participants (citizen/field staff)', 'type of contribution (active/passive)', 'type of tools', 'goal of the project', 'initiation of the project', 'development support', 'output', and 'processing/analysis' were identified. Following these codes, the findings were then grouped together to organize into categories.

\section{Findings}

Two major deliverables were developed from the study. Government interests and practices for coproducing information were categorized into four approaches and the underlying factors were also identified. These findings are discussed below.

\subsection{Approaches for coproducing geospatial information}

As indicated in Table 1, the coproduction of information is practiced in cities with a wide range of populations. Different divisions adopt coproduction approaches for various purposes. This indicates the increasing trend of involving citizens to acquire spatial information. From the several cases of coproducing spatial information, we observed four major approaches at the local level, including: collection of new data, observation of changes, collection of opinions, and observation of preferences. Each of these approaches are described in further detail, with reference to specific case study examples.

\subsubsection{Collection of new data}

Local governments often introduce projects that require new or additional data. In cases where the data is either outside their regular collection regime or data is difficult to collect within a limited time, government agencies were found to initiate coproduction processes. In most cases, this approach was used as a short-time project to experiment with a process or tool for data collection. For

Source: https://wiki.waze.com/wiki/Connected_Citizens_Program 
example, the City of Waterloo had a small project for collecting tree data with the main goal of testing a crowdsourcing tool to augment an existing database. A similar approach was used by the City of Ottawa, but with a specific plan on creating an urban forest inventory with the community with the help of the Neighbourwood app. This is a management tool used to collect tree information based on different factors that help in building an urban inventory and also to monitor and assess tree health. The tool was developed by a research team from the University of Toronto (Potts, 2008). The team supports initiating, training, and monitoring urban inventory initiatives undertaken by other entities.

The use of coproduction was also commonly used in monitoring and decision support applications. For example, the City of Johns Creek partnered with Mapillary, an open-source street view imagery repository, to create a street photo inventory where anyone can take and contribute street photos using the Mapillary app. The collected data was then used to create a more updated and seamless set of street photos of the city (Mapillary, 2016). This helps to create a large database with near real-time information. While this case used a mobile app for the project, some agencies used an online mapping platform shared through their city website to collect information for service management. For example, the City of Cambridge, as a part of their Working to Improve Neighbourhood Safety program (WINS) provided a mapping platform for the community to share their concerns regarding hazardous garbage, such as discarded needles in their area (Figure 1). This data collection process involves 'Clean up Cambridge' application, an online platform on the city government website, developed by ESRI, a leading GIS development company. The platform uses online GIS tools to get inputs from citizens about discarded needles to track drug debris (City of Cambridge, 2018). This helps the government for rapid response and to keep the environment safe. Each of these cases shows that governments provide case specific tools and platforms to collect information from citizens for better planning and service delivery. These tools used in the processes were either developed in-house or designed with the help of partners from private or research institutes. 
Figure 1: The reporting platform of the City of Cambridge for needles or other hazardous garbage

\section{Select a Location}
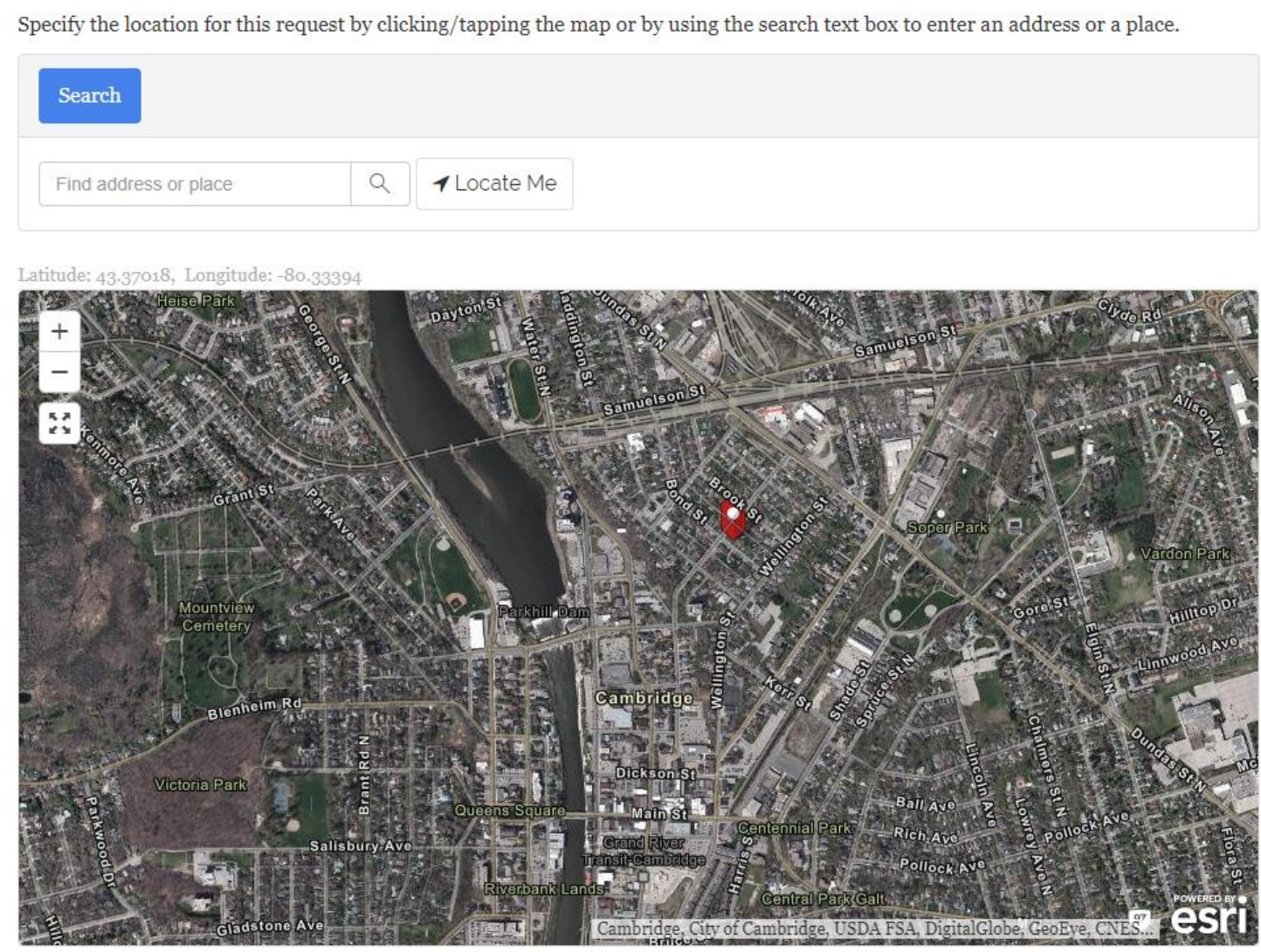

\section{Submit}

Submit your request

\subsubsection{Observation of Changes}

Despite having a comparatively frequent data collection and updating process compared to federal governments, collecting near-real time information can be challenging for local governments. Local governments were found, using different approaches, to collect more frequent information about changes involving their communities. There were two methods observed - first, using tools or platforms such as the interactive mapping platforms of the city, often with a primary goal of sharing and visualizing open data (Figure 2). Observing the authoritative data in such an interactive visual way allows users to detect features that are misplaced or not updated. Although several cases were found using this approach, this practice was predominantly used by internal field staff, who are not GIS experts but have better local knowledge due to the nature of their work. For example, as one GIS manager, discussing the use of interactive mapping platform mentioned;

"We actually use the drawing tools (embedded in the platform) for some field staff. So, we have for example, water service staff and forestry staff who will be out in the field and if they notice something that's wrong like 'look this hydrant is in the wrong place', because it was drawn in the schematic not as the actual physical location on the map, they can draw an arrow or can circle something and say, 'it's 
wrong and should be here'. And submit that in and it'll show up on the appropriate person's e-mail and then they'll go review. So, we use those drawing tools with internal stuff for that kind of communication" [Respondent H]

Figure 2: The interactive mapping platform of the City of Waterloo. The green rectangles are the sports fields from the city database while the blue rectangle is a relatively new sports field that is not in the same database but drawn with the tools from the platform.

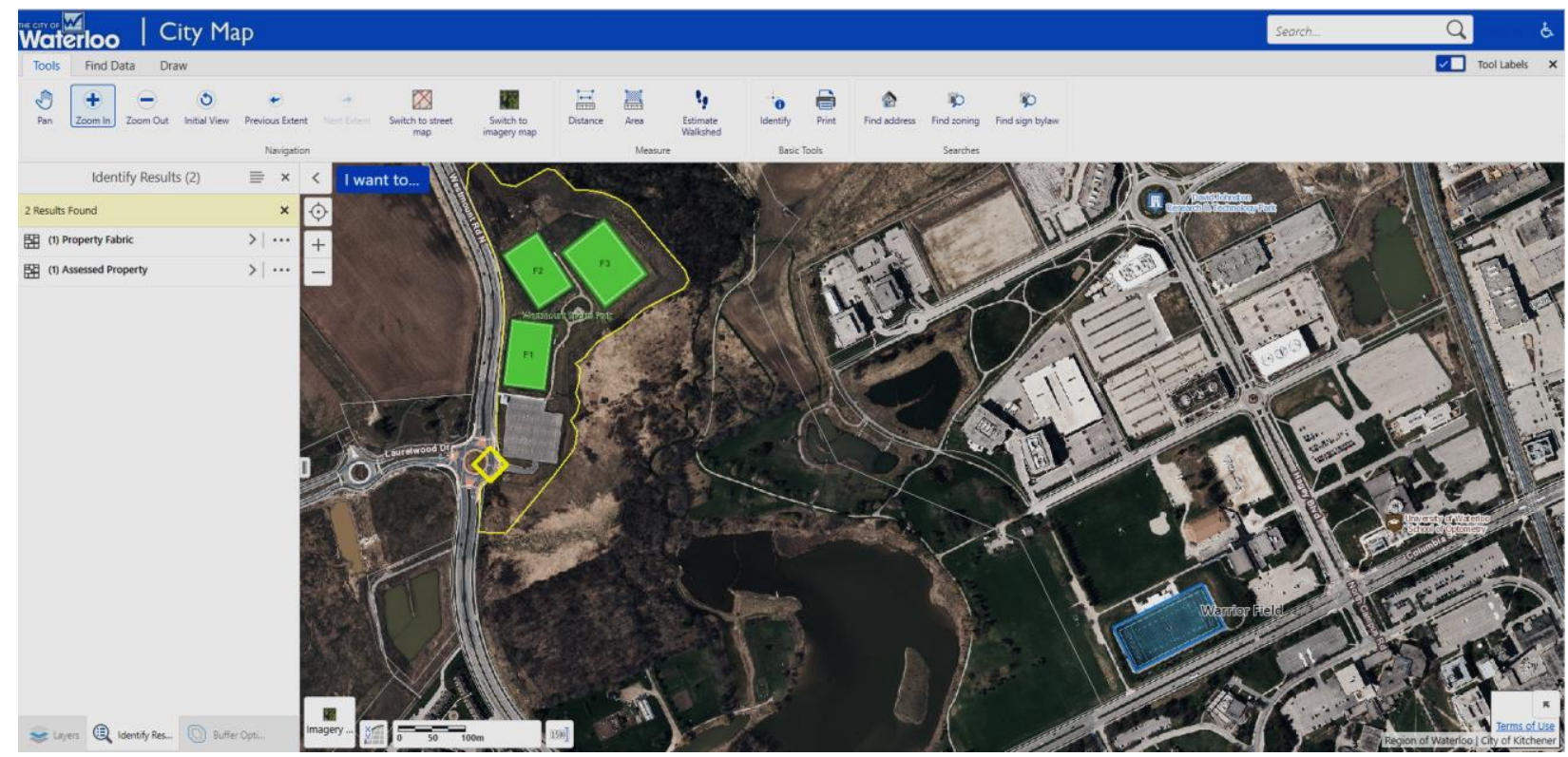

Some officials mentioned that they receive emails from citizens sharing their feedback on the municipal open data platform. All officials using this approach also acknowledged that the platform has potential for citizens to directly share their feedback, but that expanding the tasks of field staff to citizens needs more time and support from within the organization. As one interviewee mentioned;

"So, we' re talking about getting people on this (visualizing tools using open data to collect edits from community). This is part of our vision. But inside the corporation, there's multiple units involved in that. So, they really have to be comfortable of using that type of stuff." [Respondent O]

Open data platforms not only create a conduit for having more updated information through user feedback, but also uses open data to broaden and enhance engagement. Almost all of these instances identified in our study were developed by ESRI, a GIS vendor supporting local governments with visualization and analysis of spatial data.

From the interview sample, we found that Waze is partnered with a list of cities through their Connected Citizen Program, which allows governments to obtain real time traffic information from the user community of the Waze application. Through this collaboration, Waze uses road network information from the city and in exchange, shares the information collected from users including signal malfunction, road accidents, potholes, or roadkill, while driving. This helps the government to acquire live data and take rapid actions to solve problems. Respondent from the transportation division at the City of Winnipeg mentioned that although there are traditional approaches such as 
3-1-1 phone call or email systems, collaboration with Waze allows a faster and easier notification process;

"One thing that we found, even just by connecting with our traffic signal controllers and getting feedback when there were malfunctions is that when people drove through signalized intersection that will say a flashing red because of a malfunction often it would take them 20 to 30 minutes for somebody to call 3-1-1 and then that message would come in an email or other alert back to us. But having information in the form of Waze alerts or notifications means 20 to 30 minutes of congestion mitigation that we can do which is really critical for how we manage our roads." [Respondent J]

This further indicates that the contribution of citizens can significantly help governments to improve decision-making and service delivery despite the general doubt around quality of citizen contributed information. Furthermore, as citizens can share issues and observations, this coproduction approach also provides some power to the citizens to share their feedback on government information and services.

\subsubsection{Collecting opinions}

Increased interest in e-government and open government initiatives have led many cities to develop their own engagement platform with a primary objective to collect opinions from citizens. Collecting opinions involves direct communication between citizens and government to coproduce spatial information. This approach is observed in planning and community engagement, as government share planning proposals on a mapping platform to receive citizen concerns and opinions (Figure 3). Unlike the approaches previously mentioned, this involves a feedback loop between citizens and the government that acknowledges citizen contribution in the planning process, creating two-way communication between citizens and the government. Explaining the interactivity of the process, one expert from a community engagement division stated;

"One of the stages in our engagement process is that we report back to the people that have provided the feedback to us. A lot of people will say, 'well when we put our report to council then that's us reporting back' but we always push a bit more to ensure how we are letting people that took the time to participate know that at least it's going to council and they can find out what you decided and what you did with their information in that report." (Respondent G)

Officials also mentioned that the use of this coproduction approach is growing, as governments are encouraging transparency and engagement . Furthermore, along with technical supports as previously discussed, governments are also partnering for strategic support with nongovernment agencies such as International Association for Public Participation (IAP2). With both technical and strategic supports, governments are recognizing the potential of coproducing information. One planning official, using this approach, indicated the benefits as;

"It's a great way to engage with those people that can't or don't or aren't interested in coming out to an in-person meeting or workshop. So, we call them you know the silent majority and we think we can get some excellent feedback and ideas and stories that way. People are often more comfortable doing it that way. And I think for staff the data and analytics are way easier when we use it online." [Respondent G] 
Figure 3: City of Calgary collecting citizen opinions on their 'Engage' platform

\section{Closed}

What should The City consider when planning and designing flood mitigation for Bowness?

(This form is now closed. Thank you for your contributions.)

Based on your experiences and thoughts about Bowness, we would like to know what local features and sensitive areas should the project team consider in the design of the barrier. Drag the map around and use the zoom buttons at the top left of the map to find a location or feature you would like to provide a comment for. Click "add marker" and type your comment. Add as many markers as you wish.

\section{4 contributions}

2 Q Enter an address
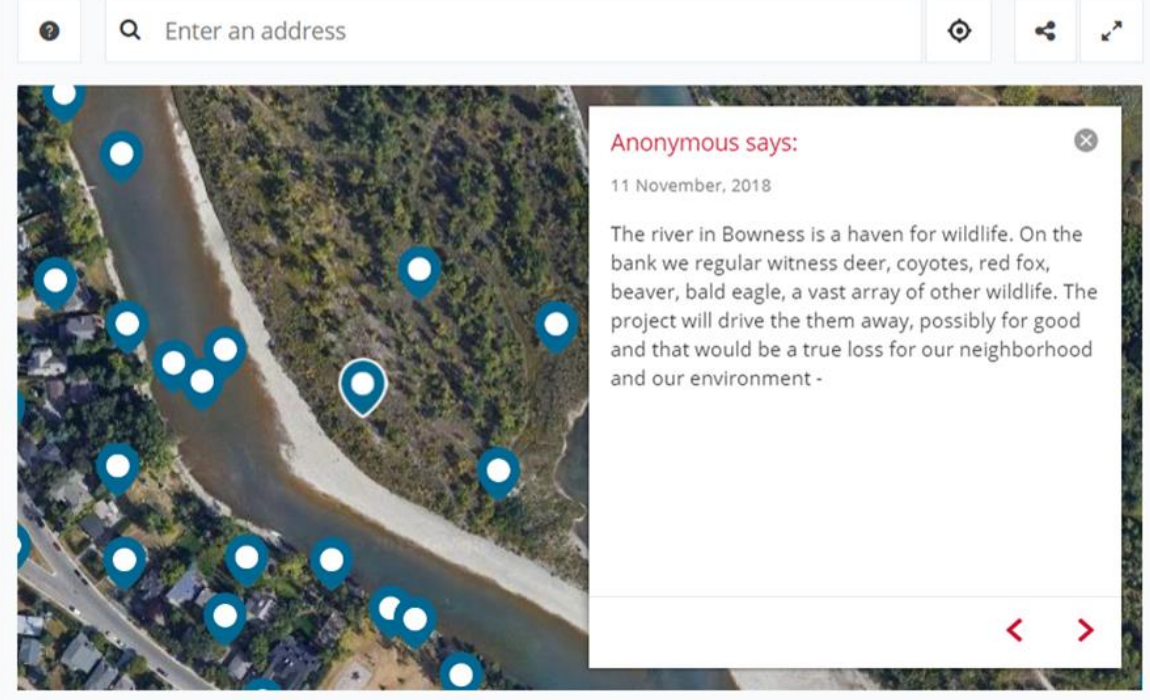

Thus, collecting data through this method can increase participation and result in better responses for planning projects, while giving the community a better chance to be heard. Local governments consider this approach as a way of practicing citizen engagement and strengthening planning processes.

\subsubsection{Observation of preferences}

Discussing the opportunities for accepting local information from citizens, many of the participating officials mentioned harvesting VGI, or collecting data passively from citizens following the notion of 'citizens as sensors' in a more technical, rather than participatory, form. For example, many officials mentioned that their city uses Twitter data to observe citizen concerns and opinions. Harvesting citizen contributed information can be used for better decision-making, with potential for augmenting existing databases. Discussing government interest in this approach, one official mentioned;

"Might not necessarily be that they're (citizens) actually capturing information but it's more like harvesting the geographic information from them, you know how Google uses all their staff to figure out based on how long you are being at a spot using a Wi-Fi connection what's a person's area. So, it could be that type of information. Understanding the patterns of people's uses we can better understand and manage and prepare the city." [Respondent D] 
Through collaboration with the Waze Connected Citizen Program, local governments can also track citizen preferences passively, and use that information to improve decision-making (Figure 4). For instance, depending on the volume of cars at specific times, a transportation division may make changes to traffic light timing. This information plays a significant role in supporting the regular functions of the transportation division [Respondent J].

Passive data is also preferred by local governments as it can reduce reliability concerns around crowdsourced data, and also requires less time and effort than active and deliberative interaction with citizens. As this approach is different than the other forms which do not require direct participation, it creates a one-way citizen to government interaction process to improve services. The processes in this approach are primarily designed and managed by third parties, as it involves significant financial, technical, time, and labor investments for developing algorithms and managing real time, large volumes of data. A GIS manager, discussed their challenges in using GPS tracks from Dockless bikeshare;

"So, we thought we were so smart, we require them (riders) to share all this data with us about the trips with those vehicles, like all GPS data and everything. But when we received the data, we realized we don't have enough people to analyze it. It is too much data for us to sit through on a regular basis. So, I think institutionally that's probably one shortcoming right now is that probably most city agencies haven't invested in a lot of staff to make use of that data." [Respondent B]

Figure 4: Waze interface. Analyzing the volume of traffic and speed limit, Waze shows fastest route for navigation. (Source: Waze)

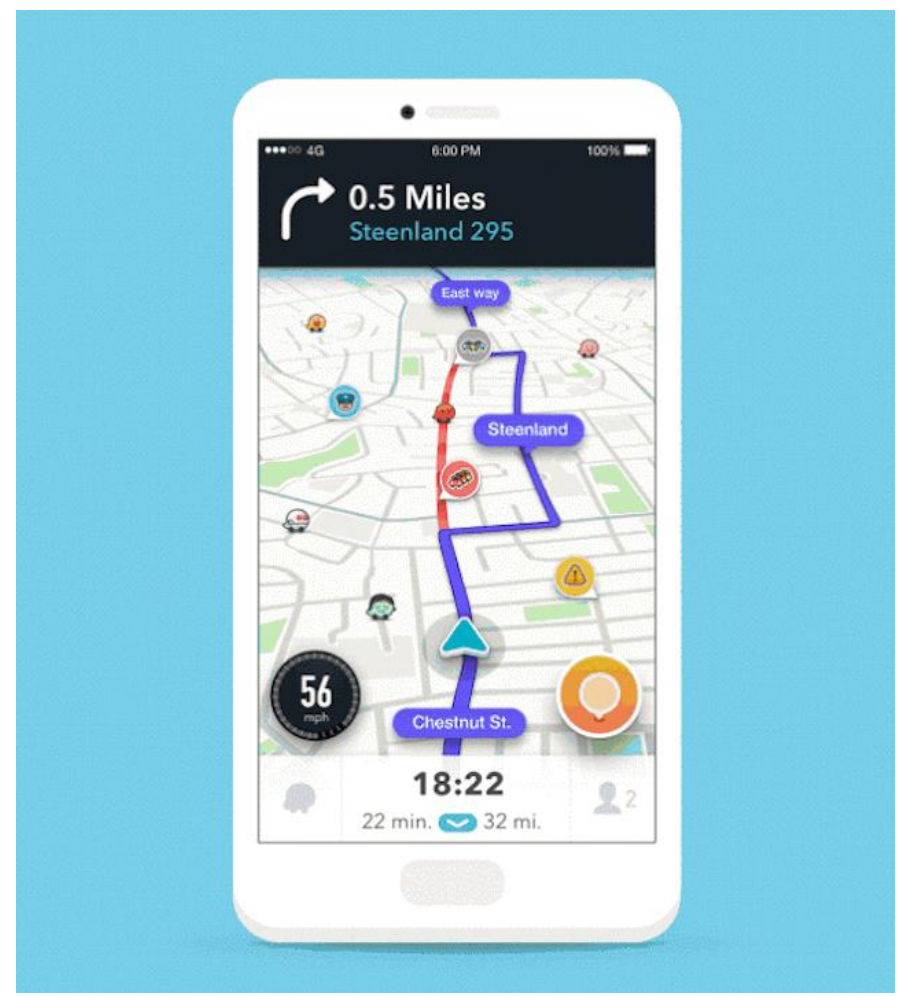


Although harvesting citizen preferences are considered to have potential, coproduction using this approach has its own development and management limitations and thus, requires significant involvement of third parties in the process. The approaches we found are building new interaction processes between citizens and the government, giving citizens, partner organizations, and government, new roles to play. During our interviews, participants also demonstrated what inspired them to coproduce spatial information, and why they prefer specific approaches. This discussion led to four factors driving coproduction of geospatial information, further elaborated below.

\subsection{Factors driving the coproducing geospatial information}

Our sample of local governments identified that motivations for collecting data come from many different areas, including availability of tools; support from private partners; improving government performance; and enhancing communication.

\subsubsection{Availability of tools}

The responses from municipal governments showed a strong connection between the availability of tools and their interest for a specific approach. The use of coproduction tools and technologies has become commonplace. As a GIS manager mentioned;

"There's a few technical challenges but they're nothing like it was 10 years ago. A lot of those things would have been really hard and really expensive. But not now. Now they're just, you know, run of the mill. We people are building 3D models and visualization tools all the time. It's no big deal." [Respondent H]

This has created opportunities for the government to experiment with new approaches for better communication and data collection. In addition, the availability of technological means such as GPSenabled mobile phones, social media such as Twitter, and ubiquitous internet, are creating opportunities for citizens to connect and participate more in these processes (Sui, Goodchild \& Elwood, 2013). The majority of coproduction cases used tools and platforms developed by a third party with a record of developing similar tools. This, along with availability, provides governments a sense of reliability in adopting them. Furthermore, officials from community engagement platforms mentioned that the online participation results in more response from citizens as those who were not comfortable in speaking in public or were unable to attend a town hall meeting could still participate (respondents C, D \& G). These availability, reliability, and convenience have created the space for better communication with citizens and in turn collecting information.

\subsubsection{Support through management process}

While technological advances have eased development costs for tools, a coproduction process also involves non-technical aspects, such as strategies for communication, management process, operational protocols, etc. Despite having coproduction tools, capacity constraints can make it difficult for government to analyze and use the data collected. This creates opportunities for partnerships with 
private or research organizations. For instance, the City of Johns Creek initiated coproducing nearreal-time street photos with the tools and data processing provided by Mapillary and ESRI (Mapillary, 2016). Similarly, the research team that developed the Neighbourwood application also supports City of Ottawa providing training to the community on how to use the app. Lastly, Waze supports cities not only with the application but also with the processing and visualization of the coproduced data. In addition, government officials also mentioned that once they experience a successful partnership in a specific context, it further encourages other divisions to implement similar ideas in other sectors to connect with citizens through coproduction.

\subsubsection{Improving governance}

There is a common issue of shrinking capacity and a lack of resources in local governments. Participating officials in our study often referred to coproduction as a way to cope with these struggles. Coproduction of spatial information not only helps government understand citizen preferences and opinions, but also enhances service delivery and decision-making. With these benefits, cities are focusing more on community engagement and citizen participation which reflect through the formation of community engagement divisions, engagement framework, and specific platforms such as 'Have Your Say' in Guelph or 'Engage" platform in Calgary for communication. The majority of these tools build on open data, further increasing transparency between citizens and government. As governments are increasingly encouraging citizen participation, engagement, and transparency (Treasury Board of Canada, 2018), coproduction approaches showcase practices in strengthening an open and transparent government. However, in some cases, there are concerns regarding the transparency of the approaches themselves. For instance, when citizens share valuable information through a third party for a specific purpose, issues such as data ownership, privacy, and transparency are often not clearly demonstrated to the stakeholders.

Partnering with companies to provide better services and communication also help governments in showcasing their performance among other government organizations. This further encourages others in following a coproduction approach. One of the officials mentioned;

"We get calls from across the country and even from the states (USA) usually asking us about developing engagement framework and that's been going on since like since 2014 ... We partnered with the community engage partnership institute for internal research at the University of Guelph and they did a huge great stand for us of provincial engagement frameworks national and then international. And from those things we got great examples and models and tools, and we sort of picked, chose, and got permission and finally, came up with what we did here. We also trained our staff in IAP2. So, you know, we are ahead of the game for other small or medium sized municipality." [Respondent G]

In addition, these interactions help cities to convey a better impression for their governance in different workshops, city councils, conferences, or competitions. For instance, during our interviews, one of the participants directed us to the project of the City of Cambridge, knowing that the city received recognition from ESRI Canada for their Clean up Cambridge app. Thus, cities are recognized for their innovative and collaborative efforts. 


\subsubsection{Better communication}

Geospatial data are collected and used for different purposes by different departments within a city government. However, city officials describe struggles regarding inter-division data sharing, which is one of the areas where open data catalogues and interactive mapping platforms provide notable benefits to organizations (Janssen, Charalabidis \& Zuiderwijk, 2012). During interviews, officials also mentioned that coproduction has open channels for both citizen-government and inter-division collaboration. One respondent discussing the challenges for data collection and management mentioned;

"Communication is one of the biggest challenges. I mean communication between groups and across intra-boundaries within the organization. Learning what changes are required is sometimes a barrier." [Respondent H]

Approaches like using the interactive mapping platform to collect updates or collecting opinions for planning purposes can help in developing inter-divisional communication. For example, the field staff at a fire department can update information regarding parks or water using the mapping tools and platforms which can be integrated into the planning databases. Similarly, sharing road closure information on Waze requires collaboration among planning, GIS, and transportation division.

Moreover, involving community to coproduce information builds trust and understanding. As explaining the objectives for creating a community based urban forest inventory, the respondent from the City of Ottawa mentioned,

"So, a huge component of our urban forest is made up of trees that are in people's backyards, or closer to people's houses so they aren't city trees. We just don't really have that information and we're very interested in figuring out how to get that information and there's a couple of programs out there that we feel like it's better if communities use them because they're more trustworthy of neighbours than the city. You know, to collect data on privately owned trees." [Respondent E]

Thus, coproducing data with community is also creating a partner-like relation with the government, which can support efficient governance. In addition, involving non-GIS experts both from within and outside the organization to contribute the information enhances internal communication and data sharing within departments.

\section{Discussion}

Several key issues and observations came up from the findings which can help in understanding the present and future of coproduction practices, clearly. Understanding how these approaches create new dynamics in political, economic, and social practices is essentially necessary and can provide useful insights for improving partnerships, policies, and government operations. The following section focuses on this with elaborate discussions. 


\subsection{Preferences and practices of citizen participation}

Different government approaches using different types of tools and platforms to coproduce information are reflective of unique government contexts and preferences. For instance, the approaches found for collecting new data were developed for a specific purpose where governments have capacity and time limitations for data collection. Studies indicate that this approach is triggered from the lack of government resources and opportunities to collect new information in a time and resource efficient way (Beaulieu, Bégin, \& Genest, 2010; Joshi \& Moore, 2004; Khan \& Johnson, 2020; Sui, Goodchild \& Elwood, 2013). Furthermore, coproducing information such as traffic conditions helps government to improve service delivery. Thus, different approaches have different aims, processes, and purposes. Naturally, not all the approaches found in our study reflect engagement or participation at the same scale. However, it is evident that the local government find these approaches beneficial to identify areas to govern better or improve service provision. The role of citizens in these approaches are often as sensors to coproduce data, needed by the government in a controlled environment, with limited options for citizens. Considering this point, we diverge with Linder's concept of coproduction results in a partner-like relationship between citizens and the government, as not all approaches to coproduction result in partnerships, and often citizens are not participating voluntarily Invalid source specified.. The findings also indicate that when it comes to coproduction, local governments prioritize providing better services, compared to citizen engagement. Voorberg, Bekkers, \& Tummers, (2015) identified that coproduction tends to emphasize service delivery and economic innovation compared to social and participatory practices, which also is reflected in our findings. Moreover, similar studies also indicate that coproduction approaches can provide less power and control to citizens Invalid source specified.. For example, compared to a social media platform like Twitter, where citizens can participate with their opinions or concerns about the city, coproduction approaches generally focus on a small specific area with selected options and functions (DePaula et al., 2018). Thus, it is important to understand that although coproduction may have a general impression of increasing social justice, increased democracy, or engagement in society, it may not always provide the opportunity to citizens to exercise these powers. However, it is undeniable that citizen involvement and contribution can improve the services and ensure better governance.

Furthermore, the use of crowdsourcing information for real-time service management was much preferred by the government. In addition, having a systematic process with the technical and strategic help from third parties, overcomes government concerns regarding the reliability on contributed information (Tenney \& Sieber, 2016). These facts indicate that the type of data collected through citizen participation vary based on government preferences, management concerns such as liability and usefulness, and available support.

\subsection{Technical and strategic limitations}

According to the responses from the participants, developing new tools and using them to collect data are not major technical barriers to implement. However, there are skills and means for developing and managing coproduction approaches that require resources not commonly found within government (Falco \& Kleinhans, 2018; Feick \& Roche, 2013; Janssen, Charalabidis, \& Zuiderwijk, 
2012; Khan \& Johnson, 2020). This drives local governments to partner with expert private or research organizations in various degrees such as from a vendor providing the basis for development, like ESRI or providing a complete system for collecting and managing information, such as Waze. We observed that although often overlooked, these partnerships play a crucial role for proper management and sustainability of the coproduction approaches including designing, maintenance, and training officials (Bucher, 2012; Johnson et al., 2015). The supports from these third parties can further increase citizen involvement and reduce technical and organizational limitations of the government including capacity, skills, and resource constraints (Johnson et al., 2015).

New initiatives are often introduced in government with the existing structures and strategies as a starting point. However, as Janssen and Zuiderwijk (2014) indicate, this often reflects in the outcome of the process, and thus requires a strong institutional and infrastructure foundation. Technical and strategic limitations direct government to build partnerships with third parties. However, platforms developed with partnerships such as through IAP2 or Waze have their own development and design approaches which fit both government and partner organization objectives, possibly benefitting both. Although government depends on the support, issues surrounding shared control and authority for development and deployment can shape the coproduction process, contributing to the neo-liberalization process in government (Sangiambut \& Sieber, 2016). For example, if there is any point where the regulation and preferences of both sides do not match, the project can stop or may provide limited support, however, the obtained data will remain to either partner or both organizations without meeting the expected outcomes. To limit these consequences, local governments need to strengthen the infrastructure and strategies that support coproduction (Janssen, Charalabidis, \& Zuiderwijk, 2012). As Bovaird (2007) mentioned "coproduction by users and communities has provided an important integrating mechanism, bringing together a wide variety of stakeholders in the public domain, although it is often hidden, frequently ignored, and usually underestimated in its potential to raise the effectiveness of public policy" (Bovaird, 2007, pp. 857-858). Hence, there should be clear and specific strategies regarding data ownership, sharing, privacy, and transparency for coproduced information to clearly outline the purpose, objective, and benefit of the approaches.

\subsection{The dynamics of control}

Allowing non-experts to contribute data is a shift towards a more participatory form of governance (Linders, 2012). Coproduction tools and platforms can provide a basis for such collaboration. However, the approaches identified in this study demonstrate different degrees of control between citizens and government. The collection of information is mostly determined by the tool and strategies set by the authorities. This approach is similar to passive crowdsourcing discussed in observation of preferences as citizens having little control, limited within their decision for participation or opting out (Reference needed). Comparatively, the collection of opinions, especially considered in planning projects, allow more freedom to think and share information. Anyone from the community, by simply dropping a point on the map, can share their opinions regarding the proposed plan of the government. However, like many citizen participation examples, it was evident that although this process can give citizens a platform to be heard, citizen involvement may come at a later phase i.e. after a proposal has already been developed (Cardullo \& Kitchin, 2018; Kahila-Tani et al., 2016; Wilson et al., 2019). Contrarily, there can be a variation of government controls over the process, as 
seen in the observation of preferences approach. For example, social media such as Twitter can let citizens post anything that concerns them, which the city officials can then extract and analyze. However, in the example of collecting passive information through GPS tracking as done in Waze, local government and partner agencies control the type of contribution depending on their preferences. Thus, looking at Arnstein's 'ladder of citizen participation', it is evident that although coproduction gives a nuance of partnership between citizens and government it shares various degrees of control with the citizens (Arnstein, 1969). Citizen involvement that we found in the approaches range within degrees of 'tokenism' with government and third parties having stronger roles to play. Looking at the design, initiation, and implementation phase of service delivery mentioned in Voorberg et al., (2015), it is clear that the citizen's involvement is significantly at the implementation level. This indicates that although coproduction with citizens is observed and often desired by the government, there are significantly fewer government approaches for cocreation of service delivery that involve the design and initiation phases.

Although government appears to have more control over the type and approach of data collection, the role of government is often shaped by partner organizations. For example, how the tools and interactions are developed, managed, and operated are a considerable part of the process. Similar to other studies, we also found that the partner organizations are commonly involved in these processes where government has little to no direct expertise (Johnson et al., 2015). These partnerships can also encourage and drive government organizations to adapt and learn to use new tools and analysis processes for making use of the collected data. Thus, the relationship between government and private organizations can share control for using coproduction tools and analyze collected data from citizens. Despite the partnership and shared control, considering the approaches and potential of the coproduction processes, governments need to build expertise to be actively involved in every part of the process (Falco \& Kleinhans, 2018; Tenney \& Sieber, 2016; Voorberg, Bekkers, \& Tummers, 2015).

Hence, we agree with Sieber and Haklay (2015), as they discussed in their analysis of knowledge production through crowdsourcing that this recent trend of information production "implies an entire underlying institutional structure of ethics, best practices, and regulations that we should assess to understand the implications." (Sieber \& Haklay, 2015, p. 132). Having a strong foundation of technical and strategic policies for coproduction can support both new and existing coproduction approaches with better management of issues, and build capacities required for successful coproduction of information.

\section{Conclusion}

Our study found that local governments follow different approaches for coproducing spatial information with citizens. Different motivating factors determine these approaches which include availability of technological means, availability of third parties for technical and strategic support, improving governance, and improving communications between citizens and government. It is a complex process where the outcomes reflect the overall motives of the stakeholders. We emphasize these complex contextual dynamics in coproduction that shape the process, which is often overlooked. The current development of digital government and the use of coproduction tools clearly indicates that tool and platform development are not a challenge for at the current stage, instead have become 
more available to both citizens and governments. However, the adoption of tools for successful use of coproduced information requires strong strategic foundation that equally emphasizes on management, analysis, and use of data.

New trends of coproduction in digital government show potential for social and economic development through better planning and service delivery, progressively involving governments in adopting various approaches. However, while citizen involvement in government often gives an impression of increased democracy, engagement, and social equity, it is important to reflect on the practices in reality. Investigating the ongoing practices can answer questions such as where is citizen involvement being practiced? What benefits do these practices bring to both governments and society? What is and can be expected from the coproduction approaches? Therefore, we argue that the research on coproduction demands an expansion of focus towards investigating the complex relationships among stakeholders and the impacts on social, cultural, and economic context of our society.

In this paper, we aimed to provide the foundation for exploring coproduction practices at local government by focusing on selected case studies. Although analyzing case studies is a useful way to bring out facts in detail, more studies on local government approaches can further help build the list of motivating factors, challenges, and impacts. More research on coproduction can further strengthen the understanding of dynamics in the process and develop comprehensive strategies for coproduction that ensure balance and benefits to all stakeholders.

\section{References}

Arnstein, S. R. (1969). A ladder of citizen participation. Journal of the American Institute of planners, 35(4), 216224.

Attard, M., Haklay, M., \& Capineri, C. (2016). The potential of volunteered geographic information (VGI) in future transport systems. Urban Planning, 1(4), 6-19.

Baack, S. (2015). Datafication and empowerment: How the open data movement re-articulates notions of democracy, participation, and journalism. Big Data \& Society, 2(2), 2053951715594634.

Bates, J. (2014). The strategic importance of information policy for the contemporary neoliberal state: The case of Open Government Data in the United Kingdom. Government Information Quarterly, 31(3), 388395.

Beaulieu, A., Bégin, D., \& Genest, D. (2010). Community mapping and government mapping: Potential collaboration. Paper presented at the Proceedings of the Symposium of ISPRS Commission I, Calgary, AB, Canada.

Bennet, D., \& Harvey, A. (2009). Publishing open government data (w3c working draft 8 september 2009). World Wide Web Consortium. http://www. w3. org/TR/2009/WD-gov-data-20090908.

Berger, B. (2009). Political theory, political science and the end of civic engagement. Perspectives on politics, $7(2), 335-350$. 
Bovaird, T. (2007). Beyond engagement and participation: User and community coproduction of public services. Public Administration Review, 67(5), 846-860.

Brabham, D. (2015). Crowdsourcing in the public sector. Georgetown University Press.

Brandsen, T., \& Honingh, M. (2018). Definitions of co-production and co-creation. In Co-Production and CoCreation (pp. 9-17). Routledge.

Bucher, T. (2012). Want to be on the top? Algorithmic power and the threat of invisibility on Facebook. New media $\mathcal{E}$ society, 14(7), 1164-1180.

Cardullo, P., \& Kitchin, R. (2019). Smart urbanism and smart citizenship: The neoliberal logic of 'citizenfocused' smart cities in Europe. Environment and Planning C: Politics and Space, 37(5), 813-830.

Chatfield, A. T., \& Reddick, C. G. (2018). All hands on deck to tweet\# sandy: Networked governance of citizen coproduction in turbulent times. Government Information Quarterly, 35(2), 259-272.

City of Cambridge. (2018). 2018 Annual report: Financial report \& consolidated financial statements. Corporate Enterprise Department, City of Cambridge.

Clark, B., \& Brudney, J. (2019). Citizen representation in city government-driven crowdsourcing. Computer Supported Cooperative Work (CSCW), 28(5), 883-910.

Craglia, M., Ostermann, F., \& Spinsanti, L. (2012). Digital Earth from vision to practice: making sense of citizen-generated content. International Journal of Digital Earth, 5(5), 398-416.

DePaula, N., Dincelli, E., \& Harrison, T. M. (2018). Toward a typology of government social media communication: Democratic goals, symbolic acts and self-presentation. Government Information Quarterly, 35(1), 98-108.

Falco, E., \& Kleinhans, R. (2019). Digital Participatory Platforms for Co-Production in Urban Development: A Systematic Review. In M. Khosrow-Pour, S. Clarke, M. E. Jennex, A. Becker, \& A-V. Anttiroiko (Eds.), Crowdsourcing: Concepts, Methodologies, Tools, and Applications (pp. 663-690). IGI Global. https://doi.org/10.4018/978-1-5225-8362-2.ch033

Falco, E., \& Kleinhans, R. (2018). Beyond technology: Identifying local government challenges for using digital platforms for citizen engagement. International Journal of Information Management, 40, 17-20.

Feick, R and R. Roche. 2013. "Understanding the value of VGI", In D. Sui, S. Elwood, and M. Goodchild (eds.), Crowdsourcing Geographic Knowledge, 15-29, New York: Springer.

Fischer, F. (2012). VGI as big data. GeoInformatics, 15(3), 46.

Ganapati, S. (2011). Uses of public participation geographic information systems applications in egovernment. Public Administration Review, 71(3), 425-434.

Goodchild, M. F. (2007). Citizens as sensors: the world of volunteered geography. GeoJournal, 69(4), 211-221.

Graves, A., \& Hendler, J. (2014). A study on the use of visualizations for Open Government Data. Information Polity, 19(1, 2), 73-91.

Haklay, M., Singleton, A., \& Parker, C. (2008). Web mapping 2.0: The neogeography of the Geoweb. Geography Compass, 2(6), 2011-2039. 
Hall, G. B., Chipeniuk, R., Feick, R. D., Leahy, M. G., \& Deparday, V. (2010). Community-based production of geographic information using open source software and Web 2.0. International Journal of Geographical Information Science, 24(5), 761-781.

Hong, S. (2016). Representative bureaucracy, organizational integrity, and citizen coproduction: Does an increase in police ethnic representativeness reduce crime?. Journal of Policy Analysis and Management, 35(1), 11-33.

Janssen, M., Charalabidis, Y., \& Zuiderwijk, A. (2012). Benefits, adoption barriers and myths of open data and open government. Information systems management, 29(4), 258-268.

Janssen, M., \& Zuiderwijk, A. (2014). Infomediary business models for connecting open data providers and users. Social Science Computer Review, 32(5), 694-711.

Johnson, P., \& Robinson, P. (2014). Civic hackathons: Innovation, procurement, or civic engagement? Review of policy research, 31(4), 349-357.

Johnson, P. A. (2017). Models of direct editing of government spatial data: challenges and constraints to the acceptance of contributed data. Cartography and Geographic Information Science, 44(2), 128-138.

Johnson, P. A., Corbett, J., Gore, C., Robinson, P., Allen, P., \& Sieber, R. (2015). A web of expectations: Evolving relationships in community participatory Geoweb projects. ACME: An International Journal for Critical Geographies, 14(3), 827-848.

Joshi, A., \& Moore, M. (2004). Institutionalised coproduction: unorthodox public service delivery in challenging environments. Journal of Development Studies, 40(4), 31-49.

Kahila-Tani, M., Broberg, A., Kyttä, M., \& Tyger, T. (2016). Let the citizens map - public participation GIS as a planning support system in the Helsinki master plan process. Planning Practice $\mathcal{E}$ Research, 31(2), 195214.

Khan, Z. T., \& Johnson, P. A. ( 2020). Citizen and government co-production of data: Analyzing the challenges to government adoption of VGI. The Canadian Geographer/Le Géographe canadien, 64, no. 3: 374-387.

Konsti-Laakso, S. (2017). Stolen snow shovels and good ideas: The search for and generation of local knowledge in the social media community. Government Information Quarterly, 34, no. 1: 134-139.

Linders, D. (2012). From e-government to we-government: Defining a typology for citizen coproduction in the age of social media. Government Information Quarterly, 29(4), 446-454.

Liu, H. K. (2021). Crowdsourcing: Citizens as coproducers of public services. Policy Internet, 1- 17. https://doi.org/10.1002/ poi3.249.

Loeffler, E., \& Bovaird, T. (2016). User and community co-production of public services: What does the evidence tell us?. International Journal of Public Administration, 39(13), 1006-1019.

Mapillary. (2016). Mastering the Collection of Open Data: Case Study of Johns Creek, GA. GIS, transportation, and smart cities.

Nelson, K. L., \& Stenberg, C. W. (2017). Managing Local Government : An Essential Guide for Municipal and County Managers. Washington, United States: SAGE Publication Inc. 
O'reilly, T. (2009). What is web 2.0: " O'Reilly Media, Inc.".

Potts, L. (2008). Neighourwoods: Inventory Protocol Or Strategic Management Planning Tool?: An Assessment of Community Implentation in Southern Ontario (Doctoral dissertation, from the Faculty of Forestry, University of Toronto).

Rahimi, S., Mottahedi, S., \& Liu, X. (2018). The Geography of Taste: Using Yelp to Study Urban Culture. ISPRS International Journal of Geo-Information, 7(9), 376.

Robinson, P. J., \& Johnson, P. A. (2016). Civic hackathons: New terrain for local government-citizen interaction? Urban Planning, 1(2), 65-74.

Sangiambut, S., \& Sieber, R. (2016). The V in VGI: Citizens or civic data sources. Urban Planning, 1(2), 141154.

Sieber, R. (2006). Public participation geographic information systems: A literature review and framework. Annals of the association of American Geographers, 96(3), 491-507.

Sieber, R. E., \& Haklay, M. (2015). The epistemology (s) of volunteered geographic information: a critique. Geo: Geography and Environment, 2(2), 122-136.

Sui, D., Goodchild, M., \& Elwood, S. (2013). Volunteered geographic information, the exaflood, and the growing digital divide. In Crowdsourcing geographic knowledge (pp. 1-12). Springer, Dordrecht.

Tenney, M., \& Sieber, R. (2016). Data-driven participation: Algorithms, cities, citizens, and corporate control. Urban Planning (ISSN: 2183-7635), 1(2), 101-113.

Thomsen, M. K., Baekgaard, M., \& Jensen, U. T. (2020). The Psychological Costs of Citizen Coproduction. Journal of Public Administration Research and Theory, 30(4), 656-673.

Thornberg, R., \& Charmaz, K. (2014). Grounded theory and theoretical coding. The SAGE handbook of qualitative data analysis (5), 153-69.

Treasury Board of Canada. (2018). Canada's 2018-2020 National Action Plan on Open Government. Ottawa: Treasury Board of Canada Secretariat.

Voorberg, W. H., Bekkers, V. J., \& Tummers, L. G. (2015). A systematic review of co-creation and coproduction: Embarking on the social innovation journey. Public Management Review, 17(9), 1333-1357.

Wilson, A., Tewdwr-Jones, M., \& Comber, R. (2019). Urban planning, public participation and digital technology: App development as a method of generating citizen involvement in local planning processes. Environment and Planning B: Urban Analytics and City Science, 46(2), 286-302.

Zhang, S. (2018). Public participation in the Geoweb era: Geosocial media use in local government.

Zhang, S., \& Feick, R. (2016). Understanding Public Opinions from Geospatial Media. International Journal of Geo-Information. 


\section{About the Author}

\section{Zarin Khan}

Zarin Khan is a geographer currently pursuing her PhD in the department of Geography and Environmental Management at the University of Waterloo. Zarin's research involves understanding the trends and evolution of geospatial data collection, management, and sharing and identifying the strategies for regulating these shifts in geospatial industry.

Dr. Peter Johnson

Peter Johnson is an Associate Professor in Geography and Environmental Management at the University of Waterloo. His research interests focus on open data, civic participation, government adoption of technology, and digital infrastructures. 